\title{
Clinical Management of Keratoconjunctivitis in Goat
}

\section{Mizanur Rahaman ${ }^{1}$ \\ Saroj Kumar Yadav² (1D) Eaftekhar Ahmed Ran ${ }^{3}$ Md. Ahaduz Zaman ${ }^{4}$}

${ }_{1,2,2}$ Department of Medicine and surgery, Chittagong Veterinary and Animal Sciences University, Khulshi, Chit -tagong-4202, Bangladesh

sEmail:shirfraaz@gmail.com

${ }^{3}$ Department of microbiology and veterinary public health, Chittagong Veterinary \& Animal Sciences University (CVASU), Bangladesh

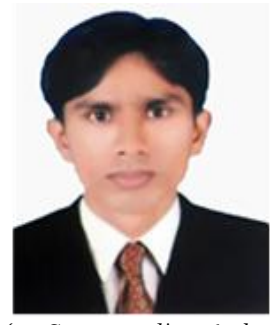

Corresponding Author

Abstract

Contagious diseases are deadly diseases in large ruminants as well as small ruminants. Present study focus on the treatment of goats infected with keratoconjunctivitis the result is very effective in this study. Duration period is one year among 2242 goats were presented at Teaching Veterinary Hospital with a different clinical condition of which 29 (1.29\%) were found keratoconjunctivitis and treated and followed the goats for 25 days and $100 \%$ success rate was seen in this study. backyard system $(79.31 \%)$ is seen as more vulnerable. the highest numbers of cases were recorded in age between 7-12 months (34.48\%) and the lowest between 13-18 months $(10.34 \%)$, and $19-24$ months $(10.34 \%)$ of age respectively. Jamnapari goats were mostly affected $(34.48 \%)$ than the indigenous breed Black Bengal (6.9\%). The p-value less than 0.05 were considered as significant in this study.

Keywords: Treatment, Keratocunjunctivitis, Goat.

Citation | Mizanur Rahaman; Saroj Kumar Yadav; Eaftekhar Ahmed Ran; Md. Ahaduz Zaman (2018). Clinical Management of Keratoconjunctivitis in Goat. Journal of Life Sciences Research, 5(1): 6-11.

History:

Received: 6 August 2018

Revised: 10 September 2018

Accepted: 16 October 2018

Published: 19 November 2018

Licensed: This work is licensed under a Creative Commons Attribution 3.0 License (c) ) EY

Publisher:Asian Online Journal Publishing Group
Contribution/Acknowledgement: The authors wish to acknowledge Shahedul Alam Kadery Teaching Veterinary Hospital, Chittagong Veterinary and Animal Sciences University, Chittagong for their technical assistance.

Funding: This study received no specific financial support.

Competing Interests: The authors declare that they have no conflict of interests.

Transparency: The authors confirm that the manuscript is an honest, accurate, and transparent account of the study was reported; that no vital features of the study have been omitted; and that any discrepancies from the study as planned have been explained.

Ethical: This study follows all ethical practices during writing.

\section{Contents}

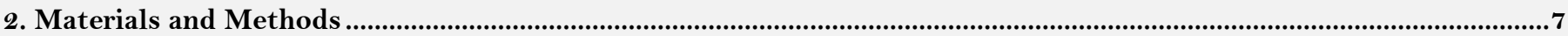

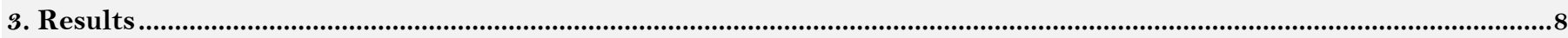

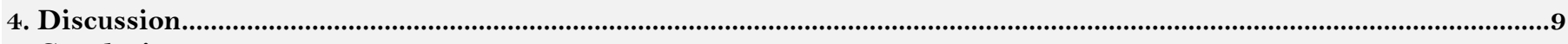

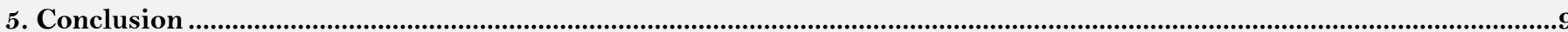

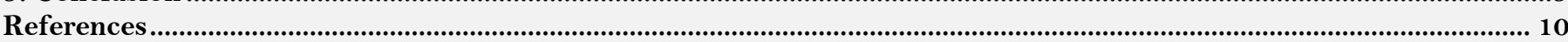




\section{Introduction}

Infectious keratoconjunctivitis (IKC) is a highly contagious disease of small ruminants caused by Mycoplasma conjunctivae and characterized by a variable degree of blindness in infected animals [1]. The disease may be associated with Chlamydophila pecorum, Pseudomonas species, Staphylococcus aureus in sheep and goat [2]. Listeria monocytogenes has also been documented with keratitis in experimental infection of sheep [3]. The prevalence of IKC is $30 \%$ at farm goat in the world [4] and at Chittagong region, it is $3.48 \%$ in goat [5]. The clinical manifestations related with IKC are mucopurulent ocular discharge, blepharospasm, red and swollen eyes, corneal opacity and photophobia [6]. The complete disease eradication is difficult because the organisms that cause the disease are widespread and may persist in carrier animals Rhaymah [2]. The disease is influenced by several factors including the immune status of the predisposed animal, virulence of the pathogenic strain involved, environmental factors and secondary infections [4]. The climatic condition of Bangladesh is tropical in nature and goat is an important sub-sector of livestock. The goat population in Bangladesh is about 25.76 million [7] and its meat contributes about 5\% to national meat production in Bangladesh [8]. An outbreak of some disease hinders this progress of which IKC is one of them due to a favorable environment for an organism and vector prevalent. IKC frequently occur when goats experience severe stress such as introduced to the new herd, transportation or relocation, and very dry or cold weather. The infection spreads easily from one eye to the other, from animal to animal and by mechanical vectors. The most important vector is considered to be the face fly (Musca autumnalis) [9]. There is no known zoonotic significance of the disease when it is caused by M. conjunctivae. Suspected IKC cases have been treated in field condition of Bangladesh with antibiotic either locally as eye drops or systemic as a parenteral injection (intramuscular) which supposed to has less efficacy. Therefore, the effective treatment protocol is required to control the disease which ultimately reduces the economic loss of the goat producers. The aim of this study is to seek and establish an effective treatment protocol against infectious keratoconjunctivitis in goat.

\section{Materials and Methods}

\subsection{Study Area and Duration}

The Teaching Veterinary Hospital (TVH) of Chittagong Veterinary and Animal Sciences University (CVASU) is the only seat of clinical learning of veterinary practices under the close supervision of the concerned teaching staff members of the clinical departments in Bangladesh. It is a busy clinic providing veterinary services for the farm and companion animals, horses, poultry etc. Most of the diseased and sick animals from different areas of Chittagong are brought to $\mathrm{TVH}$ for better treatment. Majority of patients are a goat. Due to more patient concentration and better opportunity to handle, the study was undertaken at TVH, CVASU. The study was performed from January to December 2017.

\subsection{Study Population}

The cases of IKC were identified by observing the clinical sign of eye lesions like reddening and swelling, watery or mucopurulent discharge, lacrimation, corneal opacity, photophobia and loss of vision. We considered some selective variables like age, breed, sex, body color, illness duration, housing condition, previous treatment, eye involvement, treatment duration, treatment response, lacrimation, concurrent disease, body temperature and location of the patient to identify the risk factors. We found 29 goats clinically infected with the IKC admitted at TVH of CVASU during this study period.

\subsection{Data Collection}

We prepared a questionnaire to collect patients' information. When the patients brought to the 'TVH, registration was completed by recording owners name and address. Then the questionnaire was filled up by faceto-face interview with the goat owners and close examination of the patient.

\subsection{Treatment Trial and Follow Up}

After diagnosis, all IKC infected goat patients were treated with intramuscular injection of long-acting oxytetracycline (Renamycin LA ${ }^{2}, 20 \%$, Renata limited, Bangladesh) at the dose of $20 \mathrm{mg} / \mathrm{kg}$ body weight and subconjunctival injection of dexamethasone (Dexaroid $\AA$, $2 \%$, Eskayef limited, Bangladesh) at the dose of 0.5 $\mathrm{mg} /$ eye at alternate days for 5 to $7 \mathrm{dose}$. Autohemotherapy was also administered at a dose of 3-5 ml/animal based on the body size at 5 days interval for 3 to 5 dose. Response to treatment was recorded by contact over a phone call with the owners. In some cases directly visiting the owner's home or when the patients again brought to the hospital

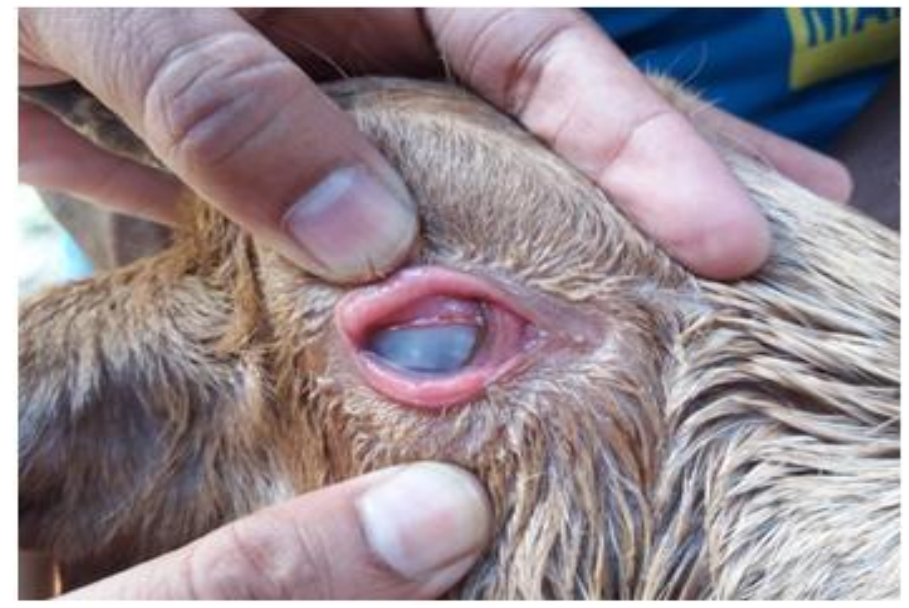

Before treatment.

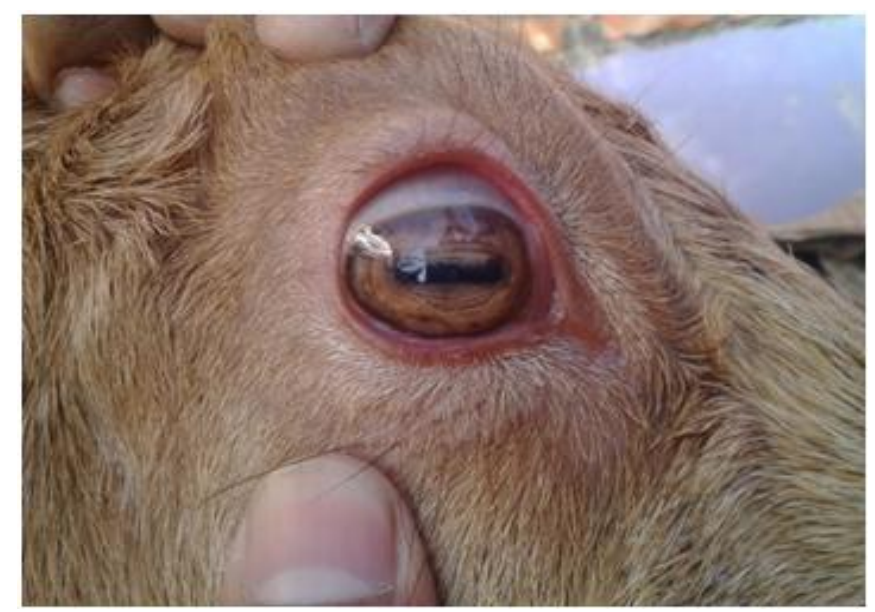

After treatment. 


\subsection{Statistical Analysis}

All data was input in Microsoft Office Excel Worksheet Program and were analyzed using STATA/IC-11.0. Significant differences among the variables were calculated using Pearson's Chi-square test. The p-value less than 0.05 were considered as significant.

\section{Results}

During our one year study period, 2242 goats were admitted at TVH with a different clinical condition of which $29(1.29 \%)$ goats were found clinically infected with IKC. During analyzing the demographic distribution of IKC cases, we found the highest number of cases were from Khushi (17.24\%) and the lowest from Chakbazar, AK Khan and Bahaddarhat (3.45\%) respectively (Table 2 ). To compare the effect of housing system on the prevalence of IKC, the maximum number of cases found in goats reared under backyard system $(79.31 \%)$ (Table 1$)$. In an agewise distribution of the disease, the highest numbers of cases were recorded in age between $7-12$ months $(34.48 \%)$ and the lowest between 13-18 months (10.34\%), and 19-24 months (10.34\%) of age respectively. Jamnapari goats were mostly affected $(34.48 \%)$ than the indigenous breed Black Bengal $(6.9 \%)$. In case of coat color, the highest numbers of cases found in brown colored goats $(41.38 \%)$ and the lowest numbers cases in white colored goats $(10.34 \%)$. Females were mostly $(65.52 \%)$ affected than males $(34.48 \%)$. Most of the goats $(82.76 \%)$ had been suffered for 1-7 days illness duration. During analyzing the clinical signs of the disease we found, rectal temperature more than $103 \mathrm{~F}(58.62 \%)$, unilateral eye involvement $(68.97 \%)$, and lacrimation (100\%) (Table 1). After treatment maximum goats $(89.66 \%)$ were recovered. The highest numbers of goat patients recovered within 8-14 days (38.46\%) and lowest numbers within 15-21 days (11.54\%). The maximum treatment response was found: in goats that were intensively housed $(100 \%)$, had $>7$ days illness duration $(100 \%)$, had body temperature between 101-103F (91.67\%), in Jamnapari and Black Bengal breed (100\%), in white colored goat (100\%) and in aged between 7-12 months, 13-18 months and 19-24 months goat (100\%) respectively and minimum treatment response were found in goats that were backyard housed (86.96\%), had 1-7 days illness duration (87.50\%), had $>103 \square \mathrm{F}$ body temperature $(88.24 \%)$, in crossbreed $(77.78 \%)$, in black and mixed colored goat $(85.71 \%)$ and in aged $>24$ months goat $(75 \%)$ (Table 3$)$.

Table-1. Frequency and percentage of different traits of goat patients infected with IKC

\begin{tabular}{|c|c|c|c|c|}
\hline \multirow{2}{*}{\multicolumn{2}{|c|}{ Traits }} & \multirow{2}{*}{\multicolumn{3}{|c|}{ Parameters }} \\
\hline & & & & \\
\hline \multirow[t]{2}{*}{ Housing } & Backyard & $\frac{\text { Frequency }}{23}$ & $\frac{\text { Percentage }}{79.31}$ & \multirow{2}{*}{$\frac{\text { P Value }}{0.00}$} \\
\hline & Intensive & 6 & 20.69 & \\
\hline \multirow[t]{2}{*}{ Illness duration (days) } & $1-7$ & 24 & 82.76 & \multirow[t]{2}{*}{0.00} \\
\hline & $>7$ & 5 & 17.24 & \\
\hline \multirow[t]{2}{*}{ Body temperature $\left({ }^{\circ} \mathrm{F}\right)$} & $101-103$ & 12 & 41.38 & \multirow{2}{*}{0.10} \\
\hline & $>103$ & 17 & 58.62 & \\
\hline Previous treatment & No & 29 & 100.00 & - \\
\hline \multirow[t]{4}{*}{ Breed } & Jamnapari & 10 & 34.48 & \multirow[t]{4}{*}{0.06} \\
\hline & Black Bengal & 2 & 6.90 & \\
\hline & Local & 8 & 27.59 & \\
\hline & Cross & 9 & 31.03 & \\
\hline \multirow[t]{4}{*}{ Color } & Black & 7 & 24.14 & \multirow[t]{4}{*}{0.05} \\
\hline & Brown & 12 & 41.38 & \\
\hline & White & 3 & 10.34 & \\
\hline & Mixed & 7 & 24.14 & \\
\hline \multirow[t]{2}{*}{ Sex } & Male & 10 & 34.48 & \multirow[t]{2}{*}{0.01} \\
\hline & Female & 19 & 65.52 & \\
\hline \multirow[t]{5}{*}{ Age (months) } & $0-6$ & 5 & 17.24 & \multirow[t]{5}{*}{0.07} \\
\hline & $7-12$ & 10 & 34.48 & \\
\hline & $13-18$ & 3 & 10.34 & \\
\hline & $19-24$ & 3 & 10.34 & \\
\hline & $>24$ & 8 & 27.59 & \\
\hline \multirow[t]{3}{*}{ Eye involved } & Right eye & 14 & 48.28 & \multirow[t]{3}{*}{0.07} \\
\hline & Left eye & 6 & 20.69 & \\
\hline & Both eye & 9 & 31.03 & \\
\hline Lacrimation & Yes & 29 & 100.00 & - \\
\hline \multirow[t]{2}{*}{ Concurrent Disease } & $\mathrm{No}$ & 26 & 89.66 & \multirow[t]{2}{*}{0.00} \\
\hline & Yes & 3 & 10.34 & \\
\hline \multirow[t]{2}{*}{ Treatment response } & $\mathrm{No}$ & 3 & 10.34 & \multirow[t]{2}{*}{0.00} \\
\hline & Yes & 26 & 89.66 & \\
\hline \multirow[t]{4}{*}{ Treatment duration (days) } & Up to 7 & 9 & 31.03 & \multirow[t]{4}{*}{0.15} \\
\hline & Up to 14 & 10 & 34.48 & \\
\hline & Up to 21 & 3 & 10.34 & \\
\hline & Up to 28 & 7 & 24.14 & \\
\hline
\end{tabular}

Source: The Teaching Veterinary Hospital (TVH) of Chittagong Veterinary and Animal Sciences University (CVASU) 2017 
Table-2. Frequency and percentage of source of patients from different location

\begin{tabular}{|c|c|c|c|c|}
\hline \multirow[t]{2}{*}{ Traits } & & \multicolumn{3}{|l|}{ Parameters } \\
\hline & & \multirow{2}{*}{$\frac{\text { Frequency }}{3}$} & Percentage & \multirow{2}{*}{$\frac{\text { P value }}{0.74}$} \\
\hline \multirow[t]{12}{*}{ Address } & Halishahar & & 10.34 & \\
\hline & Chakbazar & 1 & 3.45 & \multirow{11}{*}{0.74} \\
\hline & Pahartali & 4 & 13.79 & \\
\hline & Bayazid & 2 & 6.90 & \\
\hline & Akbarsha & 3 & 10.34 & \\
\hline & AK khan & 1 & 3.45 & \\
\hline & Moizzartak & 2 & 6.90 & \\
\hline & Khulshi & 5 & 17.24 & \\
\hline & Nasirabad & 2 & 6.90 & \\
\hline & Agrabad & 3 & 10.34 & \\
\hline & Baluchara & 2 & 6.90 & \\
\hline & Bahaddarhat & 1 & 3.45 & \\
\hline
\end{tabular}

Source: The Teaching Veterinary Hospital (TVH) of Chittagong Veterinary and Animal Sciences University (CVASU) 2017

Table-3. Correlation between treatment response and duration in goat patients

\begin{tabular}{|c|c|c|c|c|c|}
\hline \multirow[t]{2}{*}{ Treatment response } & \multicolumn{4}{|c|}{ Treatment duration (days) } & $P$ value \\
\hline & $0-7$ & $8-14$ & $15-21$ & $22-28$ & \multirow{3}{*}{0.01} \\
\hline No & $\begin{array}{l}0 \\
0.00\end{array}$ & $\begin{array}{l}0 \\
0.00\end{array}$ & $\begin{array}{l}0 \\
0.00\end{array}$ & $\begin{array}{l}3 \\
100.00\end{array}$ & \\
\hline Yes & $\begin{array}{l}9 \\
34.62\end{array}$ & $\begin{array}{l}10 \\
38.46\end{array}$ & $\begin{array}{l}3 \\
11.54\end{array}$ & $\begin{array}{l}4 \\
15.38\end{array}$ & \\
\hline
\end{tabular}

\section{Discussion}

Infectious keratoconjunctivitis is considered a worldwide disease of sheep and goats. In our study, we found $1.29 \%$ prevalence of IKC among clinical goat patients which was lower than the previous study performed by Nath, et al. [5]. At Chittagong region where they found $3.48 \%$ prevalence in farm goats' population. The lower prevalence in our clinic-based study could be due to owners' ignorance of being their goats to the hospital [4]. Stated the occurrence of disease was higher in intensive rearing system due to a spread of infection from one to another animal rapidly in Putra Malaysia that was not agreed with our findings which were more in backyard rearing system. The higher number of IKC cases found in our study in backyard rearing system could be due to a majority of goat patients in TVH from smallholders, infection from other animal and trauma to the eye during grazing $\left[10^{\circ}\right.$. Reported that clinical keratoconjunctivitis was highest in young and old animals which were probably because young animals lack immunity owing to the absence of previous exposure and in the old animal due to weak immunity. Similar findings found in this study which indicated that younger and older animals were more susceptible to the disease than adults. In this study, the occurrence of disease was more in the exotic breed that was in agreement with the report of Takele and Zerihun [10]. Which also stated that the exotic breed made them susceptible to infectious keratoconjunctivitis compared to other breeds. Periocular pigmentation is suspected to be an important risk factor for infectious keratoconjunctivitis because pigmented cattle have a higher prevalence of the disease [9]. The similar finding was observed in the present study that was a higher prevalence in brown colored goat [9]. Reported that the occurrence of disease was more susceptible in male than female. In the present study, we found females were mostly affected which could be due to injury to the eye during fighting or more susceptible to infection during stress condition [11]. Mentioned that the keratoconjunctivitis may affect one or both eyes which were in agreement with the present study. Elevated rectal temperature is a common clinical finding in infectious keratoconjunctivitis due to inflammation in the affected eye that was agreed with our findings where most of the patient had more than $103 \square \mathrm{F}$ rectal temperatures [4]. In case of infectious keratoconjunctivitis corneal opacity developed between 7 to 14 days after experimental infection in cattle which was also supported the findings of this study. Lacrimation in the infected eye was also a common clinical sign in all cases in this study due to an adhesive and inflammatory function which was similar to the findings of Mughal, et al. [3]. Some concurrent diseases like PPR and myiasis were also found in this study. PPR is a viral disease and facilitates secondary infection like infectious keratoconjunctivitis due to stress. Lacrimation facilitates more fly deposition on the eye leading to myiasis. Systemic antibiotic injections with corticosteroids subconjunctival on alternative days and installation of chloramphenicol or ciprofloxacin drop were found effective that was reducing the opacity of cornea [12], [13]. Reported that subconjunctival injections of dexamethasone reduced corneal opacity. The similar treatment protocol was followed in this study which was not practiced in our country. Autohemotherapy was also used in all cases and it is hypothesized that autohemotherapy reduced corneal opacity by enhancing humoral and cell-mediated immunity. Corneal opacity was resolved in most of the cases after 7-14 days of treatment which was also found in a study conducted by Mughal, et al. [3]. where corneal opacity was recovered completely within 7 days. Unfortunately, 3 cases were failed to recover that was due to irregularity in treatment.

\section{Conclusion}

The recovery of infectious keratoconjunctivitis in goat where developed corneal opacity was high in this study due to the report in time and immediate treatment provided. So the treatment protocol of this study could be adopted in case of that disease in goat. Isolation and molecular identification of the organism associated with infectious keratoconjunctivitis in the goat can be further studied in our country 
Table-4. Correlation of different traits with treatment response and duration in goat patients

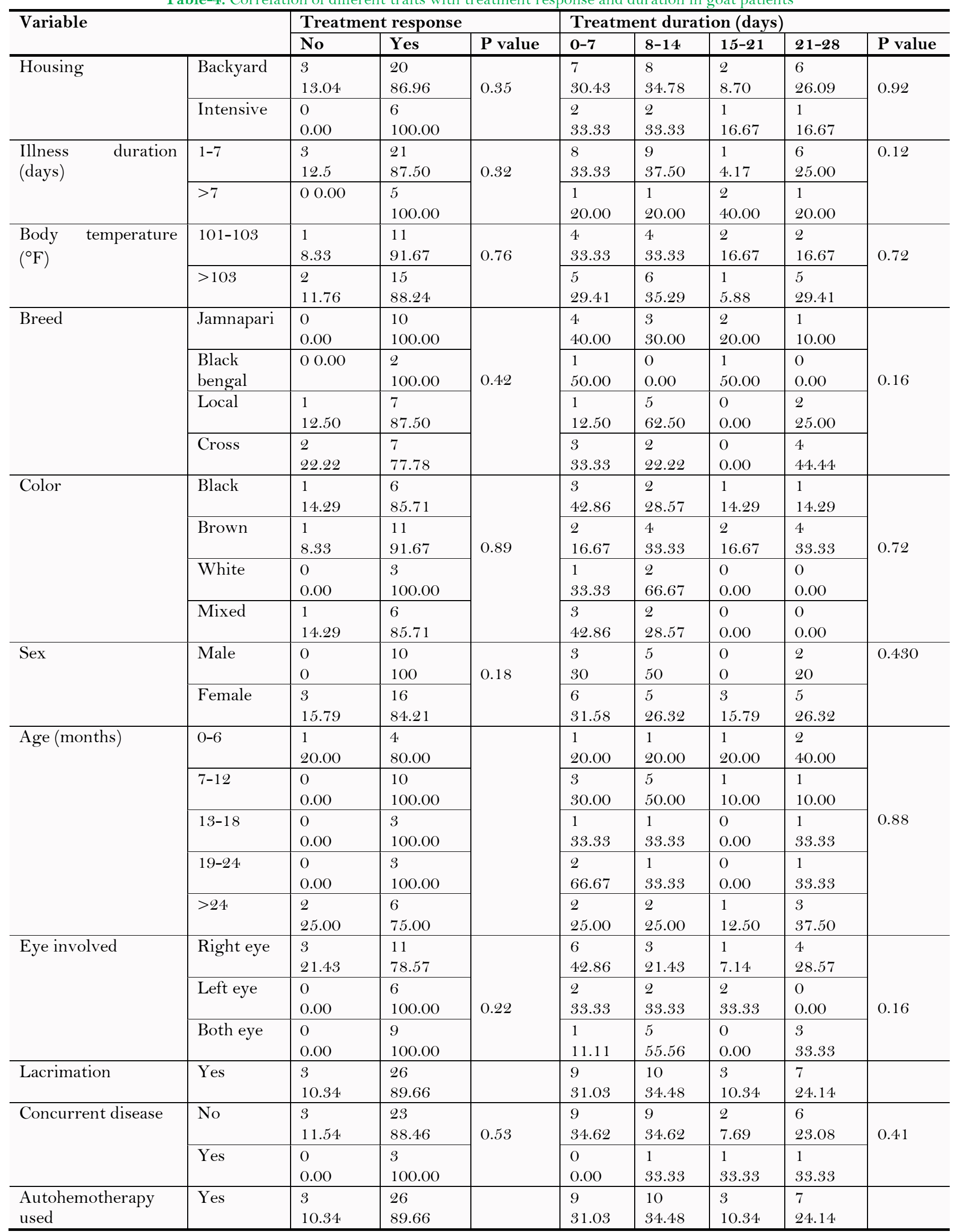

Source: The Teaching Veterinary Hospital (TVH) of Chittagong Veterinary and Animal Sciences University (CVASU) 2017

\section{References}

[1] F. J. A. Faez, A. Lawan, Y. O. Abdinasir, W. H. Abdul, and A. S. Abdul, "Clinical management of stage III infectious bovine Keratoconjunctivitis associated with staphylococcus aureus in a dairy cow: A case report," Journal of Agriculture and Veterinary Science IOSR, vol. 4, pp. 69-73, 2013.Available at: https://doi.org/10.9790/2380-0446973.

[2] M. S. Rhaymah, B. Y. Rasheed, and K. H. J. Hussain, "Comparative study on the bacterial causes of ovine keratoconjunctivitis in native breed sheep and goats," Assiut Veterinary Medical Journal, vol. 59, pp. 77-80, 2013.

[3] M. N. Mughal, A. Anwar, G. Abbas, and W. Azeem, "Infectious caprine keratoconjuctivitis in a beetal buck: A case report," International Journal of Molecular Veterinary Research, vol. 5, pp. 1-7, 2015.

[4] F. F. J. Abdullah, N. R. G. Naidu, M. A. Sadiq, Y. Abba, A. Tijjani, K. Mohammed, and A. A. Saharee, "Prevalence of moraxella ovis infection in goats under the ladang Angkat programme, Universiti Putra Malaysia: A cross-sectional study," IOSR Journal of Agriculture and Veterinary Science, vol. 8, pp. 99-102, 2015.

[5] T. C. Nath, M. J. U. Bhuiyan, M. A. Mamun, R. Datta, S. K. Chowdhury, M. Hossain, and M. S. Alam, "Common infectious diseases of goat in Chittagong districts of Bangladseh," International Journal of Scientific Research in Agricultural Sciences, vol. 3, pp. 43-49, 2014 .

[6] M. L. Browning, "Keratoconjunctivitis (Pinkeye) in goats. Extension animal scientist, Alabama A \& M University, UNP-88," p. 2, 2007. 
[7] (DLS) Division of Livestock Statistics, "Annual Report on Livestock, Ministry of Fisheries and Livestock. Farmgate, Dhaka, Bangladesh," 2016.

[8] M. A. Aziz, "Present status of the world goat populations and their productivity," Lohaman Information, vol. 45, pp. 42-52, 2010.

D. Alexander, "Infectious bovine keratoconjunctivitis: A review of cases in clinical practice," Veterinary Clinics of North America: Food Animal Practice, vol. 26, pp. 487-503, 2010.Available at: https://doi.org/10.1016/j.cvfa.2010.09.006.

[10] G. Takele and A. Zerihun, "Epidemiology of infectious keratoconjunctivitis in cattle in South-East Ethiopia," Journal of Veterinary Medicine Series A, vol. 47, pp. 169-173, 2000.Available at: https://doi.org/10.1046/j.1439-0442.2000.00274.x.

[11] I. D. Aitken, Diseases of sheep, 4th ed. Oxford: Blackwell Publishing, 2007.

$\left[12^{2}\right] \quad$ V. Ghonsikar, "Surgicotherapeutic management of anterior segment affections of eye ball in bovine," PhD Diss., MAFSU, Nagpur, 2016.

[13] D. Thakur, M. Jha, M. Shaheen, and B. Roy, "An outbreak of infectious keratoconjunctivitis in caprine and bovine in Ranchi (Bihar)," Indian Veterinary Journal, vol. 73, pp. 770-771, 1996. 